\title{
Retraction Note to: Evaluation of coracoclavicular stabilization of acute acromioclavicular joint dislocation with multistrand titanium cables
}

\author{
Tianwen Ye $\cdot$ Yueping Ouyang $\cdot$ Aimin Chen
}

Published online: 24 January 2015

(C) Springer-Verlag France 2015

Retraction Note to: Eur J Orthop Surg Traumatol

$$
\text { (2014) 24:1061-1066 }
$$

DOI 10.1007/s00590-013-1385-9

The authors have retracted this article because of double submission. This article was submitted to Acta Orthopadica Belgica in August 2013 then to the European Journal of Surgery and Traumatology (EJOST) in September 2013 which resulted in a double publication: In EJOST (October 2014, Volume 24, Issue 7, pp 1061-1066) and in Acta Orthopædica Belgica (2014, 80, 178-182). The authors take the full responsibility for this and would like to apologize Editors and readers.

The online version of the original article can be found under doi:10.1007/s00590-013-1385-9.

T. Ye $\cdot$ Y. Ouyang $\cdot$ A. Chen $(\bowtie)$

Department of Orthopaedic Surgery, Shanghai Changzheng

Hospital, Second Military Medical University, 415 Fengyang

Road, Shanghai 200003, China

e-mail: aiminchen@aliyun.com 